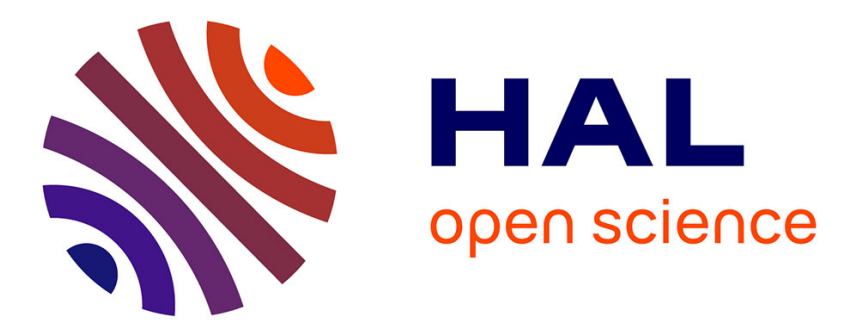

\title{
Who are these highly prolific authors in critical care?
} Chiara Robba, Emmanuel Weiss, Peter Buhl Hjortrup, Audrey de Jong, Julie Helms

\section{To cite this version:}

Chiara Robba, Emmanuel Weiss, Peter Buhl Hjortrup, Audrey de Jong, Julie Helms. Who are these highly prolific authors in critical care?. Intensive Care Medicine, 2019, 45, pp.1670-1672. 10.1007/s00134-019-05743-6 . hal-02269989

\section{HAL Id: hal-02269989 \\ https://hal.science/hal-02269989}

Submitted on 19 Jun 2020

HAL is a multi-disciplinary open access archive for the deposit and dissemination of scientific research documents, whether they are published or not. The documents may come from teaching and research institutions in France or abroad, or from public or private research centers.
L'archive ouverte pluridisciplinaire HAL, est destinée au dépôt et à la diffusion de documents scientifiques de niveau recherche, publiés ou non, émanant des établissements d'enseignement et de recherche français ou étrangers, des laboratoires publics ou privés. 


\title{
Who are these highly prolific authors in critical care?
}

\author{
Chiara Robba ${ }^{1}$, Emmanuel Weiss ${ }^{2,3}$, Peter Buhl Hjortrup ${ }^{4}$, Audrey De Jong ${ }^{5,6}$ and Julie Helms ${ }^{7,8^{*}}$
}

\section{Dear Editor,}

As asserted by W.J. Humphreys more than a century ago, "to discover is the scientist's reward, to publish is his duty" [1]. Publications are indeed contributions to world knowledge, but also the cornerstone of evidence-based medicine. Over the past decades, publishing has reached other dimensions, including a necessity and a pressure to publish ("publish or perish") for the sake of personal and/ or institutional visibility and scientific reputation. Academics often have to fulfill some publication criteria, and their research output is primarily judged on the number and the quality of their publications $[2,3]$.

Publication productivity may considerably differ depending on the medical specialty and/or the topics considered. However, characteristics and metrics of highly prolific authors have not been reported yet. We have therefore performed a study to identify highly prolific authors in critical care during the past 5 years, and analyze their characteristics and bibliometric data.

We analyzed publications in journals with a 2017-impact factor (IF) above five in the Web of Science category CRITICAL CARE MEDICINE between the 1st June 2013 and the 31st May 2018. Eight journals fulfilled the IF criteria: Lancet Respiratory Medicine, American Journal of Respiratory and Critical Care Medicine (AJRCCM), Intensive Care Medicine, Chest, Critical Care Medicine, Critical Care, Resuscitation, and Journal of Neurotrauma. We searched PubMed for original articles, conference papers, reviews, editorials, opinion articles, and letters, and excluded articles in languages other than English.

\footnotetext{
*Correspondence: julie.helms@chru-strasbourg.fr

${ }^{8}$ Hôpitaux Universitaires de Strasbourg, Service de Réanimation Médicale, Nouvel Hôpital Civil, 1. Place de L'Hôpital, 67091 Strasboura. France
}

References were analyzed with VOSviewer 1.6.9. The most frequent topics were identified through keywords, and their relatedness was determined based on the number of documents in which they occurred together. Using the association strength method for normalizing the strength of the links between items and for each of them, the total strength of the co-occurrence links with other keywords was calculated. VOS viewer was used for visualizing bibliometric networks.

Clarivate Analytics Web of Science [v5.30] database was searched for the metrics of the most prolific authors: total number of citations, total $\mathrm{H}$-index, type of articles, percentage of publications in the top $1 \%$, number of publications in each of the eight selected journals in the last 5 years, and number of publications in four major nonspecific journals in the last 5 years (New England Journal of Medicine (NEJM), Lancet, Journal of the American Medical Association (JAMA), British Medical Journal (BMJ)).

19,305 articles published by 51,891 authors were identified in Pubmed between 2013 and 2018, considering the eight critical care medicine journals with a 2017-impact factor above five (ESM Fig. 1). Among these, 83 authors were identified as having published more than 40 publications in the last 5 years. Forty of them (51\%) were European, 35 (45\%) American and 3 (4\%) Australian. Seventy-one authors (91\%) were male.

Five names were excluded, because we were unable to distinguish between several homonyms. Overall, 78 authors were included and their 4510 publications (4095 publications in the eight critical care medicine journals and 415 publications in the four major non-critical care journals) analyzed (ESM Fig. 1).

Considering the 78 authors, the median total number of publications was of 248 (IQR 173-350) and 123 (IQR 87-157) over the last 5 years (ESM Fig. 2). The median number of total citations in the Web of Science was 6880 
a

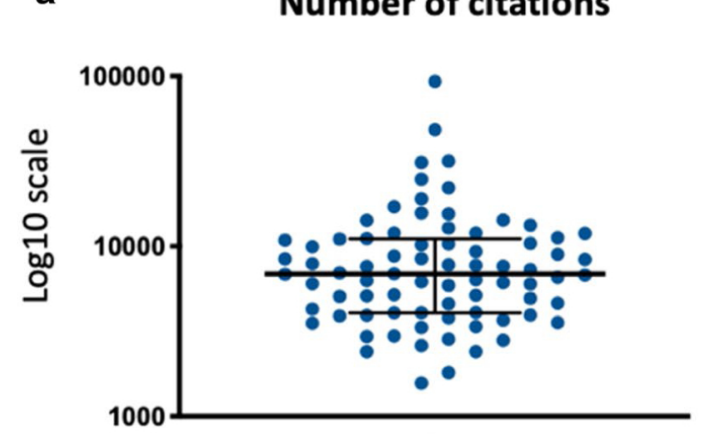

b

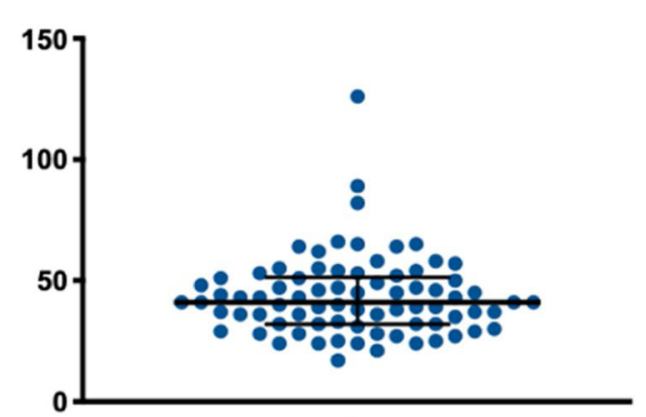

Fig. 1 Main characteristics of highly prolific authors in critical care. a Number of citations, $\mathbf{b} \mathrm{H}$-index of the highly prolific authors

(IQR 4073-11,045) and median H-index 41 (IQR 32-51) (Fig. 1a, b).

The large majority of the publications were original articles (ESM Fig. 3a). Among the eight critical care medicine journals, the articles were mostly published in Intensive Care Medicine, followed by Critical Care Medicine, Critical Care, Resuscitation and AJRCCM, and in the JAMA followed by NEJM for the four major non-critical care journals (ESM Fig. 3b). The number of publications was strongly correlated to the number of publications in the top $1 \%$ (Pearson correlation=0.62), therefore the higher was the number of articles published by an author, the higher was the chance to have publications among the top 1\% (ESM Fig. 4). Similarly, the higher the number of publications an author had among the four big journals, the higher was the chance to have publications among the top 1\% (very strong correlation of 0.92) (ESM Fig. 4).

Six clusters of main topics were identified according to the publication keywords, with first cardiac arrest, followed by traumatology, respiratory diseases, sepsis and acute respiratory distress syndrome (ESM Fig. 5). Six original articles and one conference abstract from 5 of the 78 hyperprolific authors were retracted, including two ( 1 original article, 1 abstract) within the last 5 years. Journal, dates and reasons for retractions are provided in ESM Table 1. The article concerned by the study-period was retracted because of concerns/issues with data or results, errors in data or results, lack of approval from authors, and replaced by a new manuscript.

We have tried to assess whether critical care world is affected by the current scientific plague of publication addiction and authorship hijacking, through the analysis of bibliometric data of the most prolific authors in critical care over the past 5 years.

Scientific productivity is partly reflected by the number of articles published [2]. In that respect, productivity of the most prolific critical care authors may be considered as high, with two articles per month-most of them being original ones - all the more that most of the authors combined research and clinical activity. Using this simple numerical comparator (number of publications over a time-period) to characterize an author productivity has, however, quickly made us face our limitations. Comparing the productivity of critical care authors reported here (median of 123 articles per top author over a 5-year timeperiod) with other specialties is difficult, as it spreads out from nine articles per top author over 5 years in nuclear medicine for an older time-period (2009-2013) [4], to as high as one paper every 5 days for scientists-including authors in medical and life sciences-more recently [5]. It was, however, quite consistent with the median of 93 articles per top author over 5 years in other specific medical topics like epilepsy, rheumatoid arthritis, renal transplantation and liver transplantation [3].

Publication productivity is thus highly variable depending on the medical specialty considered, and in this study, we present the main characteristics of highly prolific authors and their publications.

\section{Author details}

${ }^{1}$ Department of Anaesthesia and Intensive Care, Policlinico San Martino, IRCCS for Oncology and Neuroscience, Genoa, Italy. ${ }^{2}$ Department of Anesthesiology and Critical Care, AP-HP, Beaujon Hospital, Clichy, France. ${ }^{3}$ UMR_S 1149 Centre for Research on Inflammation, Inserm/Université de Paris, Paris, France.

${ }^{4}$ Department of Intensive Care, Copenhagen University Hospital, Rigshospitalet Blegdamsvej 9, 2100 Copenhagen, Denmark. ${ }^{5}$ PhyMedExp, University of Montpellier, INSERM U1046, CNRS UMR, 9214, Montpellier, France. ${ }^{6}$ Department of Anesthesia and Intensive Care Unit, Regional University Hospital of Montpellier, St-Eloi Hospital, Montpellier, France. ${ }^{7}$ ImmunoRhumatologie Moléculaire, INSERM UMR_S1109, LabExTRANSPLANTEX, Centre de Recherche d'Immunologie et d'Hématologie, Faculté de Médecine, Fédération HospitaloUniversitaire (FHU) OMICARE, Fédération de Médecine Translationnelle de Strasbourg (FMTS), Université de Strasbourg, Strasbourg, France. ${ }^{8}$ Hôpitaux 
Universitaires de Strasbourg, Service de Réanimation Médicale, Nouvel Hôpital Civil, 1, Place de L'Hôpital, 67091 Strasbourg, France.

\section{Compliance with ethical standards}

\section{Conflicts of interest}

A. De Jong reports personal fees from Baxter and Medtronic-Covidien, and travel reimbursements from Fresenius-Kabi, MSD France, Astellas, Pfizer and Fisher Paykel. J. Helms reports congress and travel reimbursements from Pfizer, Diagnostica Stago, MSD France, Astrazeneca and Gilead Sciences. E. Weiss reports personal fees form Baxter, MSD France and Biomerieux, and travel reimbursements from MSD France and Eumedica. The other authors have no conflict of interest to declare.

\section{References}

1. Humphreys WJ (1909) The Duty of publishing. Science 30:177-179

2. Buratti $L$ (2009) Where are italian anesthesiologists and intensive care specialists publishing? A quantitative analysis of publication activity. HSR Proc Intensive Care Cardiovasc Anesth 1:48-52

3. Wager E, Singhvi S, Kleinert S (2015) Too much of a good thing? An observational study of prolific authors. PeerJ 3:e1154

4. McKellar C, Currie G (2015) Publication productivity in nuclear medicine. J nucl med technol 43:122-128

5. Ioannidis JPA, Klavans R, Boyack KW (2018) Thousands of scientists publish a paper every five days. Nature 561:167-169 